\title{
Identification, synthesis and characterization of a novel antimicrobial peptide HKPLP derived from Hippocampus kuda Bleeker
}

\author{
Dandan Sun, Songqing Wu, Chenfeng Jing, Ning Zhang, Dong Liang and Anlong Xu
}

A novel gene encoding 55 amino-acid residues has been identified from the brooding pouch cDNA library of Hippocampus kuda Bleeker. The deduced amino-acid sequence is highly homologous to several pleurocidin-like peptides from the winter flounder and comprises a signal peptide, a pro-peptide and a mature peptide. The glycine-rich mature peptide, designated HKPLP, contains 24 amino-acid residues and has been synthesized by solid-phase peptide synthesis. The purified HKPLP exhibits antimicrobial activity against several Gram-positive and Gram-negative bacterial strains at low concentrations (MIC 1.5-7.5 $\mu \mathrm{M}$ ). Thermal stability assay data show good heat stability. CD spectroscopy experiments indicate that the dominant contents are anti-parallel and parallel sheets, which may have $\beta$-sheet or $\beta$-strand motif. It is inferred that HKPLP participates in the host defense during egg fertilization and embryo development as an antimicrobial peptide in brooding pouch.

The Journal of Antibiotics (2012) 65, 117-121; doi:10.1038/ja.2011.120; published online 18 January 2012

Keywords: antimicrobial activity; antimicrobial peptides; HKPLP; peptide synthesis

\section{INTRODUCTION}

Antimicrobial peptides (AMPs) are broadly defined as an abundant group of small (12-50 amino acids) proteins with $2-9$ positively charged lysine or arginine residues and considered to be potential candidates as therapeutic medicines or food additives. ${ }^{1}$ AMPs have been characterized from widely distributed sources, such as invertebrate, plant, insect, bird and mammal species. To date, over 1500 different AMP sequences have been identified. ${ }^{2,3}$

The majority of AMPs are characterized by an amphipathic structure, composed of hydrophobic and cationic amino acids. These molecules display both cationic and hydrophobic surfaces, ${ }^{4}$ and this is considered as a prerequisite for the disruption of biological membranes and direct cell lysis. Other mechanisms of antimicrobial action are, however, also possible including inhibition of cell wall, protein or nucleic-acid biosynthesis or binding to heat-shock proteins. ${ }^{5-7}$ Owing to these activities, AMPs can act as a first line of defense against invading pathogens, and they are considered to be important components of the innate immune systems of various animal species. ${ }^{8-10}$

The AMPs were initially identified during biochemical purification, whereas recently, more and more putative novel AMPs have been found by molecular biological techniques via expressed sequence tag analyses and gene cloning. ${ }^{11,12}$

A putative AMP HKPLP consists of 24 amino-acid residues, which is encoded by a novel gene from the brooding pouch cDNA library of
Hippocampus kuda Bleeker, a seahorse used as a traditional Chinese medicine. In our previous work, the HKPLP peptide was expressed successfully in $P$. pastoris with the secretion vector pPICZ $\alpha$ A, avoiding the harm of product toxicity to the host. However, the engineering strain was genetically unstable and prone to gene silencing. ${ }^{13}$ In the present study, solid-phase peptide synthesis approach was adopted to gain the HKPLP peptide. After purification, the molecular mass was identified by MALDI-TOF, and then the antimicrobial activity spectrum was investigated, as well as heat stability. The $\mathrm{CD}$ spectrum indicated that antiparallel and parallel sheets structures were dominant contents. It was assumed that the secondary structural motif and glycine-enriched nature have a key role in the antimicrobial activity of HKPLP.

\section{MATERIALS AND METHODS}

Sequence analysis

The total RNA of brooding pouch tissue from the Hi. k. Bleeker collected in an aquaculture farm in China was isolated using Trizol reagent (Invitrogen, Carlsbad, CA, USA). A cDNA library was constructed and 3372 cDNA clones were sequenced as described previously. ${ }^{14}$ On the basis of the sequence alignment and NCBI BLAST, a new gene named $h k p l p$ was isolated, then the sequence data were deposited to NCBI (GenBank ID: AY864343). ${ }^{14}$

\section{Peptide synthesis}

The HKPLP peptide (FLGLIFHGLVHAGKLIHGLIHRNR-NH ${ }_{2}$ ) was assembled according to a standard Fmoc-protocol using Rink resin with $0.45 \mathrm{mmol} \mathrm{g}^{-1}$

State Key Laboratory of Biocontrol, Guangdong Province Key Laboratory of Pharmaceutical Functional Genes, National Engineering Research Center of South China Sea Marine Biotechnology, Department of Biochemistry, College of Life Sciences, Sun Yat-sen University, Guangzhou, China

Correspondence: Professor A Xu, State Key Laboratory of Biocontrol, Guangdong Province Key Laboratory of Pharmaceutical Functional Genes, National Engineering Research Center of South China Sea Marine Biotechnology, Department of Biochemistry, College of Life Sciences, Sun Yat-sen University, Guangzhou, 510275, China. E-mail: Issxal@mail.sysu.edu.cn

Received 17 September 2011; revised 15 November 2011; accepted 18 November 2011; published online 18 January 2012 
loading capacity as described previously. ${ }^{15}$ The amino-acid residues were coupled using HOBt/HBTU/DIPEA (1:1:0.9) for $2 \mathrm{~h}$. The peptide was removed from the resin by a $3 \mathrm{~h}$ treatment with reagent R (90\% TFA: $5 \%$ thioanisole: $3 \%$ 1,2-ethanedithiol: $2 \%$ anisole). After cleavage, the crude peptide was precipitated with anhydrous diethyl ether by centrifugation at 4000 r.p.m. for $10 \mathrm{~min}$. The pellets were washed twice by diethyl ether, and then lyophilized.

\section{Purification and identification}

The crude production was dissolved in distilled water and purified by RPHPLC on a Waters $\mathrm{C}_{18}$ column $(4.6 \times 250 \mathrm{~mm}, 5 \mu \mathrm{m}, 300 \AA)$ using a linear gradient of $5-60 \%$ solvent $B$ in $50 \mathrm{~min}$, solvent $A$ was $0.1 \%(v / v)$ TFA in water and solvent $\mathrm{B}$ was $0.1 \%(\mathrm{v} / \mathrm{v})$ TFA in $100 \%$ acetonitrile. The flow rate was $1 \mathrm{ml} \mathrm{min}^{-1}$. The separation was monitored by UV absorbance at $215 \mathrm{~nm}$.

The identity of the peptide was confirmed by MALDI-TOF (Bruker Daltonics REFLEX III, Germany). The sample (in 30\% acetonitrile $/ 0.1 \%$ TFA) was treated with $\alpha$-cyano-4-hydroxycinnamic acid.

\section{Antimicrobial activity}

Peptide concentrations were determined using BCA Protein Assay kit (Pierce, Appleton, WI, USA), and zone-of-inhibition assay was performed on the following strains: the Gram-negative bacteria Escherichia coli, Enterococcus faecium and Salmonella choleraesuis, the Gram-positive bacteria Staphylococcus haemolyticus and Staphylococcus aureus.

Bacteria were grown at $37^{\circ} \mathrm{C}$ in broth medium. When reached in midlogarithmic phase, the cells were poured into agar plates. After solidification, a gel punch ( $2 \mathrm{~mm}$ in diameter) was used to make evenly spaced wells and $10 \mu \mathrm{l}$ HKPLP was added to each well, and a parallel $500 \mu \mathrm{g} \mathrm{ml}^{-1}$ Ampicillin was added as a positive control. Plates were incubated for $3 \mathrm{~h}$ at $37^{\circ} \mathrm{C}$ and then turned over and incubated for a further $12 \mathrm{~h}$. Then the clear zones around the wells could be visualized and examined.

The antibacterial activity of HKPLP was quantitatively analyzed using the bacterial and fungi strains listed in Table 2, as previously described. ${ }^{16}$ Briefly, the bacteria were grown in the appropriate medium and then portioned into a 96-well plate with $10^{6}$ cells per well, treated with the peptide at a series of concentrations. The MIC was defined as the lowest peptide concentration giving $>50 \%$ inhibition of the test organism compared with the control, measured at $630 \mathrm{~nm}$. Measurements were done three times.

\section{Thermal stability assay}

To analyze the thermal stability of HKPLP, it was dissolved in $10 \mathrm{~mm}$ phosphate buffer ( $\mathrm{pH}$ 6.0). and exposed to various temperatures ranging from 20 to $100{ }^{\circ} \mathrm{C}$ for $30 \mathrm{~min}$. The antimicrobial activity was investigated by agar diffusion assay using $S$. aureus with untreated samples (at room temperature) as positive control and phosphate-buffered saline as a negative control. All assays were performed twice.

\section{CD spectroscopy}

CD spectrum was carried out in an Applied Photophysics Spectropolarimeter. The sample was dissolved to a final concentration of $200 \mu \mathrm{M}$ in sterilized distilled water and added into a $10 \mathrm{~mm}$ quartz cuvette. The measurements were performed over 190-260 $\mathrm{nm}$ wavelength range at room temperature using an average of three scans.

\section{RESULTS}

\section{Sequence analysis}

A novel gene was obtained by random sequencing of the cDNA library. The sequences of such a cDNA clone and the deduced peptide are shown in Figure 1. The $435 \mathrm{bp}$ cDNA sequence contained an ORF of $168 \mathrm{bp}$ that was predicted to encode a peptide of 55 amino acids, which consisted of signal peptide, mature peptide and pro-peptide. Through BLAST analysis and alignment, the full-length peptide had 87 percent similarity (70\% identities) to $\mathrm{Hb} 26$ derived from Hippoglossus hippoglossus ${ }^{17}$ and 80 percent similarity (59\% identities) to PLE3 derived from Pseudopleuronectes americanus, ${ }^{18}$ respectively (Figure 2). The physical and chemical property of the mature peptide compared
1 atg aag tgg aca get gca ttc ctg gtt ctg gtc atc gtg gtg ctg atg gca cag cec gga

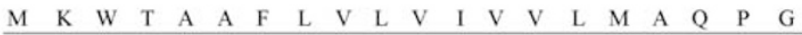

61 gag tgt ttt ttg gga ctc att ttt cac ggc ctg gtt cac gec gga aag ctg atc cac ggg

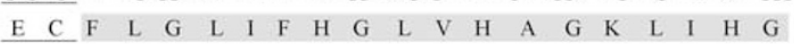

$121 \mathrm{ttg}$ atc cac agg aat cge gge ttt gaa gag caa gag gag ctc ttc tag

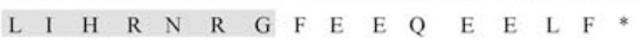

Figure 1 The ORF and predicted amino-acid sequences of $h k p / p$. The predicted mature region is in gray shadow, pro-region is in bold, signal peptide region is underlined and * indicates the stop codon.

$$
\text { signal peptide }
$$$$
\text { mature peptide }
$$

HKPLP MKWTAAFLVLVIVVLMAQPGEC FL.GLIFHGLVHAGKL.IHGLIIHRNRG FEEQEFL.F

Hb26 MKFTATFLVLFMVVLMAEPGEC FLGLLFGVHHVGKWIHGLIHGHHG YDEQQELDKRAVDE PLE3 MKFTATFLVLSLVVLMAEPGEC FLGALIKGAIHGGRFIHGMIQNHHG YDEQQELNKRAVDE

Figure 2 Sequence alignment of HKPLP with other homologous AMPs. The mature regions are boxed, and the pro-peptide regions are underlined.

Table 1 Comparison of physical and chemical property of HKPLP with other homologous antimicrobial peptides

\begin{tabular}{|c|c|c|c|c|c|c|}
\hline & \multirow[b]{2}{*}{ Charge } & \multirow[b]{2}{*}{$M W$} & \multirow{2}{*}{\multicolumn{2}{|c|}{ Number of Isoelectric point }} & \multicolumn{2}{|c|}{ Hydropathy } \\
\hline & & & $\begin{array}{c}\text { Number of } \\
\text { residues }\end{array}$ & & $\begin{array}{c}\text { Hydrophobic } \\
\text { amino acid (\%) }\end{array}$ & $\begin{array}{c}\text { Hydrophillic } \\
\text { amino acid (\%) }\end{array}$ \\
\hline $\mathrm{Hb} 26$ & +5.5 & 2749 & 24 & 8.80 & 46 & 54 \\
\hline PLE3 & +5.0 & 2625 & 24 & 11.0 & 45 & 55 \\
\hline HKPLP & +6.0 & 2719 & 24 & 12.0 & 48 & 52 \\
\hline
\end{tabular}

In order to estimate the net charge, $\mathrm{K}, \mathrm{R}$ and $\mathrm{C}$-terminal amidation was assumed to have values of $+1, \mathrm{H}$ was assumed to have a value of $+1 / 2, \mathrm{D}$ and $\mathrm{E}$ was assumed to have values of -1 .

with Hb26 and PLE3, as shown in Table 1. Both Hb26 and PLE3 belonged to pleurocidin-like peptides. The physical and chemical property of the mature peptide were compared with $\mathrm{Hb} 26$ and PLE3, as shown in Table 1. Thus, the novel peptide of this work is proposed to be a new pleurocidin-like peptide. According to posttranslational modification principles, a putative proteolytic cleavage site existed, we suggested that the mature peptide containing 24 amino-acid residues with the glycine following arginine was processed to a C-terminal amide, ${ }^{19-21}$ and designated HKPLP (Hi. K. Bleeker pleurocidin-like peptide).

\section{Peptide synthesis and MS}

The peptide HKPLP was synthesized by Fmoc method. The overall yield of peptide based on the initial starting resin was $\sim 20 \%$. After purification, the RP-HPLC profile and mass spectra were obtained. As shown in Figure 3, the fractions by RP-HPLC displayed a single distinct peak with the $\mathrm{m} / z$ signal at $2717.279 \mathrm{Da}$ corresponding to an average mass of $2716.279 \mathrm{Da}$. The theoretical monoistopic mass of HKPLP was $2717 \mathrm{Da}$ and the value was consistent with an amidated C-terminus $(-1 \mathrm{Da})$.

\section{Antimicrobial activity}

Inhibitory-zone assays confirmed that peptide HKPLP indeed had a capacity of killing bacteria, including some animal pathogenic and spoilage microorganisms, as shown in Figure 4.

The MIC results indicated that Staphylococcus aureus were the most sensitive bacteria to peptide HKPLP at $1.5 \mu \mathrm{M}$, E.coli $\mathrm{K}_{12} \mathrm{D}_{31}$ and strains of pathogenic Staphylococcus were also inhibited at concentration of $3-15 \mu \mathrm{M}$. HKPLP could also inhibit the growth of fungi at 
a

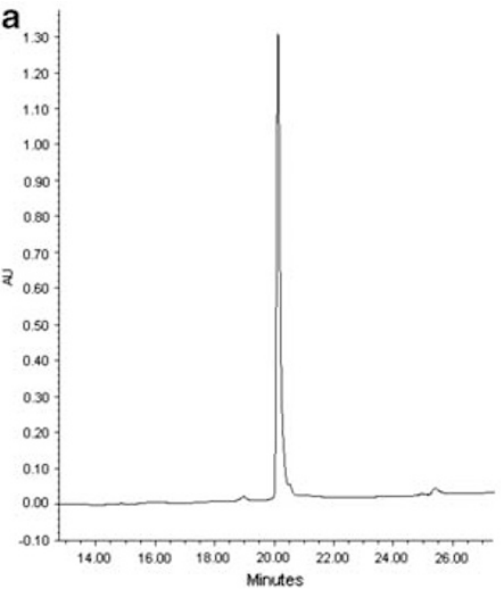

b

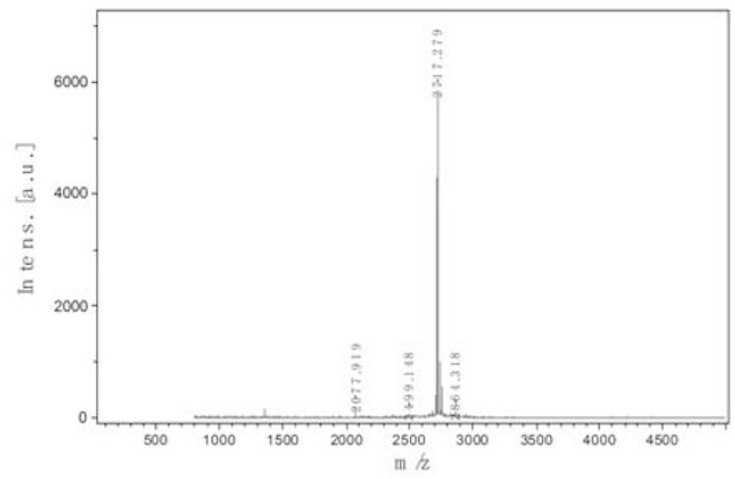

Figure 3 RP-HPLC and mass spectra. (a) The distinct peak is synthetic HKPLP. (b) The $\mathrm{m} / \mathrm{z}$ signal at 2717.279 corresponds to an average mass of 2716.279 Da. The theoretical monoistopic mass of HKPLP was 2716 Da with an amidated C-terminus. A full color version of this figure is available at The Journal of Antibiotics journal online.

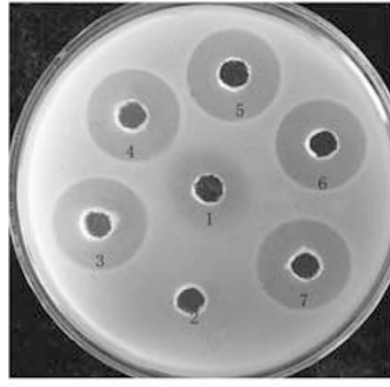

E.coli $\mathrm{DH} 5 \alpha$

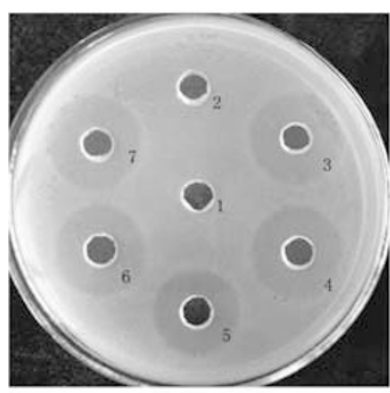

Enterococcus faecium

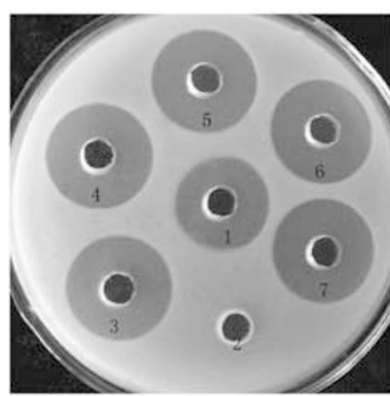

Staphylococcus haemolyticus

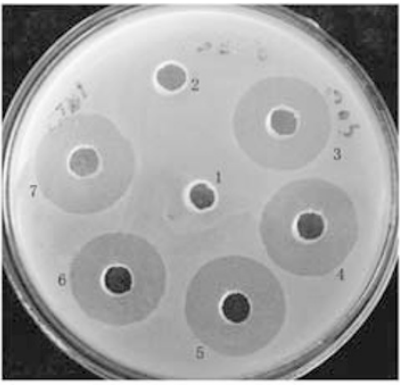

E.coli $\mathrm{K}_{12} \mathrm{D}_{31}$

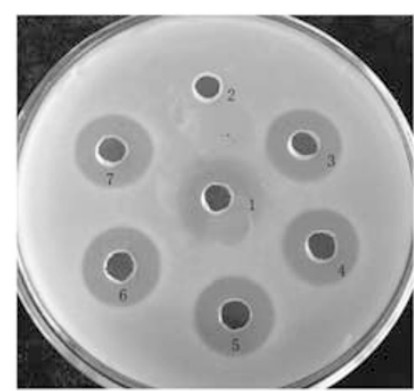

Salmonella choleraesuis

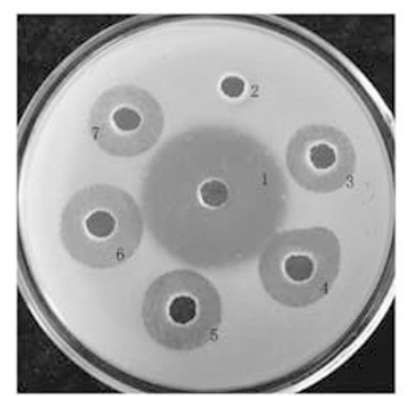

Staphylococcus aureaus

Figure 4 Inhibitory zone assay of HKPLP on growth of several bacteria. Well 1: positive control (Ampicillin, $500 \mu \mathrm{g} \mathrm{ml}^{-1}$ ); Well 2: negative control; Well 3-7: purified HKPLP peptide $\left(500 \mu \mathrm{g} \mathrm{ml}^{-1}\right)$. A full color version of this figure is available at The Journal of Antibiotics journal online.

Table 2 Antimicrobial activities of peptide HKPLP determined by MIC

\section{Strains}

$\operatorname{MIC}(\mu \mathrm{M})$

\section{Gram-positives}

Staphylococcus aureaus

Staphylococcus haemolyticus

Staphylococcus saprophyticus

Staphylococcus warneri

Bacillus subtilis

\section{Gram-negatives}

E.coli $\mathrm{K}_{12} \mathrm{D}_{31}$

Salmonella choleraesuis

E.coli $\mathrm{DH} 5 \alpha$

Morganella morganii

Enterococcus faecium

Vibrio damsela

Fungi

Candida albicans 96

$\begin{array}{ll}\text { Saccharomyces cerevisiae } & 384\end{array}$

relatively high concentrations (96 and $384 \mu \mathrm{M}$, respectively), as shown in Table 2.

\section{Thermal stability assay}

Most AMPs are stable to high temperatures, so HKPLP might also possess heat stability. It was noted that HKPLP retained its full activity after exposing to temperature ranging from 20 to $80^{\circ} \mathrm{C}$ for $30 \mathrm{~min}$, and only about $20 \%$ of activity was lost when boiling at $100{ }^{\circ} \mathrm{C}$ for $30 \mathrm{~min}$. These results suggest that HKPLP was not significantly affected by temperatures up to $100^{\circ} \mathrm{C}$.

\section{CD spectroscopy}

We determined the structural property of HKPLP using CD spectroscopy and the absorption curve presented $\mathrm{v}$-shaped spectra indicating $\beta$-sheet, ${ }^{22}$ as shown in Figure 5. 


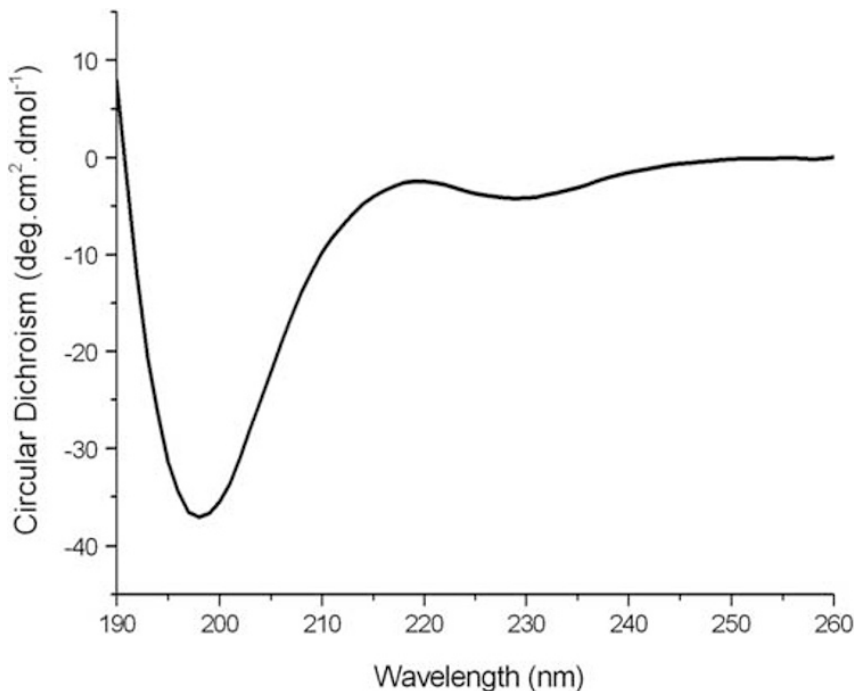

Figure $5 \mathrm{CD}$ spectroscopy. The $\mathrm{CD}$ spectrum is recorded at $25^{\circ} \mathrm{C}$ in the low UV region $(190-260 \mathrm{~nm})$. Antiparallel and parallel sheets structures are the dominant content $(>60 \%)$.

The percent helical and sheet content was calculated using the method proposed by Baldwin ${ }^{23}$ and the data revealed that there were $48.1 \%$ antiparallel and $13.4 \%$ parallel sheets structures in peptide HKPLP, suggesting that HKPLP might adopt $\beta$-sheet or $\beta$-strand motif instead of $\alpha$-helix.

\section{DISCUSSION}

In the chemical synthesis of HKPLP, the hydrophobic and sterically hindered amino acids brought some trouble in the coupling reaction, and therefore we lengthened the coupling time and adjusted the $\mathrm{pH}$ between 6 and 7, then obtained the cationic peptide in higher yield.

A definite classification of AMPs is yet not established, based on the structural features, they are usually divided into $\alpha$-helical, cysteine rich, specific amino acid-enriched and miscellaneous categories. ${ }^{24,25}$ The specific amino acid-enriched peptides from marine species include the proline-rich, ${ }^{26-28}$ arginine-rich ${ }^{29,30}$ and glycine-rich. ${ }^{31}$

Hyastatin, an $11.7 \mathrm{kDa}$ glycine-rich (11.6\%, 15 glycines in 129 total residues) peptide from the spider crab hemocytes, ${ }^{31}$ possesses activity against Gram-positive and Gram-negative bacteria as well as fungi. HKPLP has similar high glycine content (16.7\%, 4 glycines in 24 total residues) as Hyastatin, but contains no cysteines, whereas C-terminus region of Hyastatin contain 6 Cys residues. The glycine-rich character along with three positive-charged amino-acid residues makes HKPLP exert antimicrobial activity.

The native Hyastatin shows high activity against Gram-positive bacterium Corynebacterium glutamicum (MIC $0.4 \mu \mathrm{M}$ ) and yeasts (MIC $12.5 \mu \mathrm{M}$ ). Although HKPLP has less activity than Hyastatin against yeasts (MIC $>100 \mu \mathrm{M}$ ), it exhibits more activity against some Gram-positive (S.aureus) and Gram-negative (E.coli) bacteria. Both of Hyastatin and HKPLP have their own merits.

We have isolated another AMP named HKABF from Hi. k. Bleeker, which comprises hydrophobic sequences followed by the positivecharged domain KKRR. ${ }^{16}$ HKABF belongs to cysteine-rich peptides, and $\mathrm{CD}$ spectrum indicates that it contains $\mathrm{CS} \alpha \beta$ motif, whereas HKPLP possesses $\beta$-sheet rather than cysteine and belongs to specific amino acid-enriched peptides. It implies that HKPLP and HKABF adopt different secondary structures although both exhibit antimicrobial activity and are produced by the same species.
It is inferred that AMPs including HKPLP and HKABF constitute the innate immune system along with other factors such as natural killer cell enhancement factor (NKEF), antioxidant proteins, and lectins in Hi. K. Bleeker and participate in the host defense during the fertilization and development of eggs in vivo, which is correlated with paternal brooding pattern. This mechanism has a very important role in primitive vertebrates with low specificity and rapid response time.

Overall, our study has revealed that HKPLP has strong antimicrobial activity and heat stable property in vitro, and may participate in protection against infectious pathogens as antimicrobial agents in the brooding pouch. These data encourage further investigations of the potential of HKPLP as a drug or food additive.

\section{ACKNOWLEDGEMENTS}

This work was supported by a grant from Guangzhou Haizhu District ScienceTech Program (No.2010-C-10).

1 Hancock, R. E. \& Scott, M. G. The role of antimicrobial peptides in animal defenses. Proc Natl Acad Sci U S A 97, 8856-8861 (2000).

2 Brahmachary, M. et al. ANTIMIC: a database of antimicrobial sequences. Nucleic Acids Res 32, D586-D589 (2004).

3 Thomas, S., Karnik, S., Barai, R. S., Jayaraman, V. K. \& Idicula-Thomas, S. CAMP: a useful resource for research on antimicrobial peptides. Nucleic Acids Res 38, D774-D780 (2010).

4 Brown, K. L. \& Hancock, R. E. Cationic host defense (antimicrobial) peptides. Curr Opin Immunol 18, 24-30 (2006).

5 Yonezawa, A., Kuwahara, J., Fujii, N. \& Sugiura, Y. Binding of tachyplesin I to DNA revealed by footprinting analysis: significant contribution of secondary structure to DNA binding and implication for biological action. Biochemistry 31, 2998-3004 (1992).

6 Patrzykat, A., Friedrich, C. L., Zhang, L., Mendoza, V. \& Hancock, R. E. Sublethal concentrations of pleurocidin-derived antimicrobial peptides inhibit macromolecular synthesis in Escherichia coli. Antimicrob Agents Chemother 46, 605-614 (2002).

7 Otvos, L. Jr et al. Interaction between heat shock proteins and antimicrobial peptides. Biochemistry 39, 14150-14159 (2000).

8 Yeaman, M. R. \& Yount, N. Y. Mechanisms of antimicrobial peptide action and resistance. Pharmacol Rev 55, 27-55 (2003).

9 Brogden, K. A. Antimicrobial peptides: pore formers or metabolic inhibitors in bacteria? Nat Rev Microbiol 3, 238-250 (2005).

10 Hancock, R. E., Brown, K. L. \& Mookherjee, N. Host defence peptides from invertebrates - emerging antimicrobial strategies. Immunobiology 211, 315-322 (2006).

11 Gueguen, Y. et al. Characterization of a defensin from the oyster Crassostrea gigas. Recombinant production, folding, solution structure, antimicrobial activities, and gene expression. J Biol Chem 281, 313-323 (2006).

12 Gonzalez, M. et al. Molecular characterization of two isoforms of defensin from hemocytes of the oyster Crassostrea gigas. Dev Comp Immunol 31, 332-339 (2007).

13 Grunweller, A. \& Ehrenhofer-Murray, A. E. A novel yeast silencer. the $2 \mathrm{mu}$ origin of Saccharomyces cerevisiae has HST3-, MIG1- and SIR-dependent silencing activity. Genetics 162, 59-71 (2002).

14 Zhang, N. et al. Molecular profile of the unique species of traditional Chinese medicine, Chinese seahorse (Hippocampus kuda Bleeker). FEBS Lett 550, 124-134 (2003).

15 Sun, D. et al. Structure-function relationship of conotoxin It14a, a potential analgesic with low cytotoxicity. Peptides 32, 300-305 (2011).

16 Wang, L. et al. Production and characterization of a novel antimicrobialpeptide HKABF by Pichia pastoris. Process Biochem 43, 1124-1131 (2008).

17 Patrzykat, A., Gallant, J. W., Seo, J. K., Pytyck, J. \& Douglas, S. E. Novel antimicrobial peptides derived from flatfish genes. Antimicrob Agents Chemother 47, 2464-2470 (2003).

18 Douglas, S. E., Gallant, J. W., Gong, Z. \& Hew, C. Cloning and developmental expression of a family of pleurocidin-like antimicrobial peptides from winter flounder, Pleuronectes americanus (Walbaum). Dev Comp Immunol 25, 137-147 (2001).

19 Boman, H. G. Peptide antibiotics and their role in innate immunity. Annu Rev Immunol 13, 61-92 (1995).

20 Arzese, A., Skerlavaj, B., Tomasinsig, L., Gennaro, R. \& Zanetti, M. Antimicrobial activity of SMAP-29 against the Bacteroides fragilis group and clostridia. J Antimicrob Chemother 52, 375-381 (2003).

21 Bagella, L., Scocchi, M. \& Zanetti, M. cDNA sequences of three sheep myeloid cathelicidins. FEBS Lett 376, 225-228 (1995).

22 Ranjbar, B. \& Gill, P. Circular dichroism techniques: biomolecular and nanostructural analyses-a review. Chem Biol Drug Des 74, 101-120 (2009).

23 Scholtz, J. M., Qian, H., York, E. J., Stewart, J. M. \& Baldwin, R. L. Parameters of helixcoil transition theory for alanine-based peptides of varying chain lengths in water. Biopolymers 31, 1463-1470 (1991). 
24 Smith, V. J., Desbois, A. P. \& Dyrynda, E. A. Conventional and unconventional antimicrobials from fish, marine invertebrates and micro-algae. Mar Drugs 8, 12131262 (2010).

25 Barra, D., Simmaco, M. \& Boman, H. G. Gene-encoded peptide antibiotics and innate immunity. Do 'animalcules' have defence budgets? FEBS Lett 430, 130-134 (1998).

26 Schnapp, D., Kemp, G. D. \& Smith, V. J. Purification and characterization of a prolinerich antibacterial peptide, with sequence similarity to bactenecin-7, from the haemocytes of the shore crab, Carcinus maenas. Eur J Biochem 240, 532-539 (1996).

27 Khoo, L., Robinette, D. W. \& Noga, E. J. Callinectin, an Antibacterial Peptide from Blue Crab, Callinectes sapidus, Hemocytes. Mar Biotechnol (NY) 1, 44-51 (1999).
28 Dolashka, P. et al. Antimicrobial proline-rich peptides from the hemolymph of marine snail Rapana venosa. Peptides 32, 1477-1483 (2011).

29 Stensvag, K. et al. Arasin 1, a proline-arginine-rich antimicrobial peptide isolated from the spider crab, Hyas araneus. Dev Comp Immunol 32, 275-285 (2008).

30 Cuthbertson, B. J. et al. Diversity in penaeidin antimicrobial peptide form and function. Dev Comp Immunol 32, 167-181 (2008).

31 Sperstad, S. V., Haug, T., Vasskog, T. \& Stensvag, K. Hyastatin, a glycine-rich multidomain antimicrobial peptide isolated from the spider crab (Hyas araneus) hemocytes. Mol Immunol 46, 2604-2612 (2009). 